\title{
Bauxite Residue Valorization and Best Practices: Preface for the Thematic Section and Some of the Work to Follow
}

\author{
Yiannis Pontikes ${ }^{1}$
}

Published online: 10 November 2016

(C) The Minerals, Metals \& Materials Society (TMS) 2016

The management of bauxite residue, also known as red mud, ${ }^{1}$ continues to be a challenge for the alumina industry. More than 150 million tonnes of bauxite residue is produced annually, and a number of legacy sites still remain, asking for attention. Yet, from a different perspective, bauxite residue can be seen as a resource, a material that has already started being used in industrial processes, and that will continue to be, more and more in the future. This was in fact the introduction of the opening call, back in 2014, asking for contributions on how to transform bauxite residue into a valuable raw material, a call asking academia and industry to identify and promote jointly novel, exciting, but also realistic and scientifically sound solutions.

The outcome of this effort was a successful conference. A total of 45 papers and almost 150 registrations were the warmest possible response from the community, underlining that there is still room for creativity and innovation, despite years of research on bauxite residue. The papers were grouped in four thematic areas that can be also identified as four research areas, as well as the steps of a broader, zero-waste approach:

- from bauxite to a bauxite residue for neutralization, revegetation, and beyond;

- recovery of $\mathrm{Fe}, \mathrm{Al}$, and $\mathrm{Ti}$;

- recovery of minor elements and REE; and

- cement, concrete, ceramics, and novel applications.

The contributing editor for this article was S. Kitamura.

Yiannis Pontikes

yiannis.pontikes@kuleuven.be

1 KU Leuven, Leuven, Belgium
The wide variety of papers, covering such an extensive range of applications, suggested that a universal approach is perhaps not realistic, but a regional-based solution is more appropriate and easier to be industrially adapted, considering that it addresses the needs of the locals. At the same time, the communication of these innovative ideas planted the seeds for interdisciplinary work and innovation to grow.

A small contribution to this path is the dedicated thematic section in the Journal of Sustainable Metallurgy, included in the current issue (vol. 2, issue 4). The preface herein serves as the introduction to the seven selected papers.

The work of Evans [1] sets the scene. It presents efforts of years, while giving a perspective for the future. Indeed, in spite of over a century of effort looking for uses, over 1200 patents and hundreds of technically successful trials, less than 4 million tonnes of the 150 million tonnes of bauxite residue produced annually is used in a productive way. The paper discusses the barriers and why technical successes do not always translate into large-scale uses. Still, there are cases where the residue is being used, the most successful large-scale applications being cement production, raw material for iron and steel production, use in building materials, landfill capping, road construction, and soil amelioration. Some of the more recent promising developments are also presented and some of the drives behind these evolutions are analyzed. In conclusion, it is underlined that "public, corporate, and government attitudes have never presented such an encouraging

\footnotetext{
${ }^{1}$ Red mud and bauxite residue are often used as terms interchangeably, and this will be followed also herein. Please note, however, that bauxite residue does not imply a slurry/fluid state and is often used to denote the dry content of red mud.
} 
environment for developing and implementing bauxite residue uses."

The work continues with a paper by Mayes et al. [2], providing an update on the environmental risks that are associated with the Ajka spill accident, in Hungary, in 2010. This event has been registered as the largest single release of bauxite residue to the environment, and since then there have been 46 scientific studies assessing the key risks and impacts associated with it. These studies have provided insight into the main environmental concerns, as well as the effectiveness of remedial efforts that can inform future management of bauxite residue elsewhere. The key immediate risks after the spill were associated with the highly caustic nature of the red mud and fine particle size, which, once desiccated, could generate fugitive dust. Studies on affected populations showed no major hazards identified beyond caustic exposure, while red mud dust risks were considered equal to or lesser than those provided by urban dusts of similar particle size distribution. The longer-term environmental risks were related to the saline nature of the spill material (salinization of inundated soils) and the release and the potential cycling of oxyanionforming metals and metalloids in the soil-water environment. However, extensive management efforts in the aftermath of the spill greatly limited these exposure risks through leachate neutralization and red mud recovery from the affected land. Monitoring of affected soils, stream sediments, waters, and aquatic biota has shown a very rapid recovery toward pre-spill conditions. Ironically, the accident prompted research that has highlighted the potential benefits of red mud use for critical raw material recovery, carbon sequestration, biofuel crop production, and use as a soil ameliorant.

The next work is by Angelopoulos et al. and focused on the drying of red mud [3]. This is indeed an unavoidable step in many high-temperature processes that aim to use the residue, and can be seen as the process that follows after the initial dewatering. In the current study, drying kinetics and energetics of red mud obtained from filter presses of Aluminum of Greece were studied. Drying experiments were performed under isothermal conditions over a wide temperature range $\left(50-250{ }^{\circ} \mathrm{C}\right)$ and 10 thin-layer models were employed for simulation of temporal evolution of moisture removal. Three statistical error factors were implemented in order to test models' accuracy, and it was found that Midilli et al.'s equation showed the best fit $\left(R^{2}>0.99\right)$. The effective moisture diffusivity and activation energy were also estimated.

The following work by Kaußen and Friedrich [4] compared three processes, aiming to maximize Al recovery. Bauxite residue from a legacy site was used. By following the Bayer process once again, it was found that substantial amounts of $\mathrm{Al}$ can be recovered. Even mild conditions, like
$150{ }^{\circ} \mathrm{C}$ at $200 \mathrm{~g} / \mathrm{l} \mathrm{NaOH}$ or $250{ }^{\circ} \mathrm{C}$ at $100 \mathrm{~g} / \mathrm{l} \mathrm{NaOH}$, can extract almost half of the $\mathrm{Al}$ content. After optimizing the process, up to $70 \%$ of the $\mathrm{Al}$ content can be recovered without the simultaneous leaching of silica. Reductive smelting of bauxite residue with lime addition created a slag phase with considerably high Al contents. The extraction of $\mathrm{Al}$ from calcium aluminate slags requires high digestion temperatures of $>250{ }^{\circ} \mathrm{C}$. Higher $\mathrm{NaOH}$ concentrations of $>500 \mathrm{~g} / \mathrm{l}$ can be used to extract almost the entire $\mathrm{Al}$ content. The best combination of high $\mathrm{Al}$ recoveries and low silicon concentrations in the leachate was achieved with the $\mathrm{Na}_{2} \mathrm{CO}_{3}$ sinter process. To achieve Al recoveries above $70 \%$, the sintering temperature should be $>900{ }^{\circ} \mathrm{C}$ and the $\mathrm{Na}_{2} \mathrm{CO}_{3}$ addition should be $\geq 35 \mathrm{wt} \%$, calculated over the mass of treated red mud. The addition of lime up to a $\mathrm{CaO} / \mathrm{SiO}_{2}$ of 1.1 improves $\mathrm{Al}$ extraction, lowers the silicon concentration in the leachate, and assures a subsequent crystallized aluminum hydroxide product of comparable purity to the one of the Bayer process. Moreover, the addition of coke in order to reduce the hematite to metallic iron improves Al recovery further. Finally, the $\mathrm{NaOH}$ concentration in the leachate compared to the Bayer process is very low and simplifies the winning of aluminum hydroxide in the subsequent crystallization step. This process is cost intensive and necessitates recovery/recycling of sodium; yet, it offers a range of benefits and might even be interesting for fresh bauxite residues.

The next work sheds light on a timely topic. With more than 100 papers analyzed, this review by Borra et al. [5] explores the recovery of rare earth elements (REEs), possibly alongside other valuable metals, from bauxite residue. REEs can be recovered from bauxite residue by direct leaching or by smelting followed by leaching. The main disadvantages of direct acid leaching are the consumption of large amounts of acid for neutralization, the handling of large volumes of effluents, and the difficulty in using the bauxite residue after leaching. Recovery of iron prior to leaching can improve the economics of the process. However, high alumina in the bauxite residue increases the flux and acid consumption. Therefore, alumina needs to be removed by alkali roasting prior to smelting in order to decrease the flux and acid consumption. The alkali roasting-smelting-leaching process allows the recovery of aluminum, iron, titanium, and REEs from bauxite residue. The residue generated in this process can be used in building materials and cementitious binders. Other processes with commercial potential are the Orbite, the pressure leaching, and the acid baking processes.

On a different application front, red mud is used as a catalyst in the work of Alharthi et al. [6] Two aspects were studied: one was methane cracking over red mud, modified red mud, and waste from a nailwork factory site and the other was the application of different hydrocarbons, 
including nitrogen-containing precursors over red mud. Preliminary characterization of the resulting carbon deposits was performed. The activity for methane cracking increased when the red mud was activated and reduced before the reaction. Nitrogen-containing reactants led to the formation of nitrogen-doped carbon nanotubes. The nitrogen amount and morphology varied with the precursor used and the reaction temperature. This is an attractive application with potential for further modification of the carbon deposits for other catalytic and electrochemical applications.

The last work of the thematic section herein is by Hertel et al. [7]. The authors suggested a new process, turning bauxite residue into a ready-made mortar for the synthesis of inorganic polymers. Once this process is used after the Bayer process, the whole cycle is effectively transformed into a near-zero-waste process. The first step of the process is firing bauxite residue at $1100{ }^{\circ} \mathrm{C}$, which supports the formation of liquid phase and results after subsequent fast cooling in a semi-vitreous material. Based on thermodynamic calculations, the process was subsequently improved by adding minor quantities of $\mathrm{C}$ and silica to bauxite residue before firing, which leads to the carbothermic reduction of ferric iron into ferrous iron. The new blends demonstrated an increase in the melt formation and eventually in the content of amorphous phase after solidification. The resulting material was activated using a $\mathrm{K}$-silicate solution and was cured at $60{ }^{\circ} \mathrm{C}$ for $72 \mathrm{~h}$. The synthesized materials were water insoluble and dense, demonstrating compressive strength exceeding $40 \mathrm{MPa}$ for the silica-rich blend. These inorganic polymers can find applications in construction, such as pavement tiles or floor/roofing tiles. A possible implementation of the process to transform bauxite residue within the alumina refinery was also represented.

Considering the number and quality of the papers received, as well as the industrial involvement, we feel that this conference, and the ones to follow in 2018 and 2021 (...), will facilitate and accelerate the transition toward more "sustainable metallurgy." There are strong indications indeed that the timing might be just right for bauxite residue to be treated as a resource.

\section{References}

1. Evans K (2016) The history, challenges, and new developments in the management and use of bauxite residue. J Sustain Metall 2(4). doi:10.1007/s40831-016-0060-x

2. Mayes WM, Burke IT, Gomes HI, Anton ÁD, Molnár M, Feigl V, Ujaczki É (2016) Advances in understanding environmental risks of red mud after the Ajka spill, Hungary. J Sustain Metall 2(4). doi:10.1007/s40831-016-0050-z

3. Angelopoulos PM, Balomenos E, Taxiarchou M (2016) Thin-layer modeling and determination of effective moisture diffusivity and activation energy for drying of red mud from filter presses. J Sustain Metall 2(4). doi:10.1007/s40831-016-0055-7

4. Kaußen FM, Friedrich B (2016) Methods for alkaline recovery of aluminum from bauxite residue. J Sustain Metall 2(4). doi:10. 1007/s40831-016-0059-3

5. Borra CR, Blanpain B, Pontikes Y, Binnemans K, Van Gerven T (2016) Recovery of rare earths and other valuable metals from bauxite residue (red mud): a review. J Sustain Metall 2(4). doi:10. 1007/s40831-016-0068-2

6. Alharthi AI, Hargreaves JSJ, Pulford ID, Gupta N, Balakrishnan M, Batra VS, Singh RK (2016) Hydrocarbon cracking over red mud and modified red mud samples. J Sustain Metall 2(4). doi:10. 1007/s40831-016-0082-4

7. Hertel T, Blanpain B, Pontikes Y (2016) A proposal for a $100 \%$ use of bauxite residue towards inorganic polymer mortar. J Sustain Metall 2(4). doi:10.1007/s40831-016-0080-6 